\title{
Annotation
}

\section{Living with a mentally handicapped brother or sister}

For all children, home is the best place to be brought up. Plenty of evidence has accumulated that children's homes and other similar institutions, however well equipped and well trained the staff, are less good at fostering optimal development than the ordinary affectionate family. The child with a mental handicap is as susceptible to these family influences as the normal sibling. But does the presence of a child with a mental handicap, who needs more parental attention over a longer period, make that home a less good environment for the other potentially normal children? Should parents feel that they are being forced to sacrifice the well being of one child for the sake of another? Should parents who already have children of their own be allowed to adopt another with particular difficulties and more than the usual range of needs?

Families vary widely not only in their initial reaction to a distressing event but how they cope with the problems later. The notion that a family with a handicapped child must be a handicapped family is offensive to many and discredited from evidence of recent research. Emphasis now is put on the variety of strengths as well as the weaknesses of the people concerned. ${ }^{1}$

\section{Sharing of family grief}

No parent experiences the realisation that a child is handicapped-and hence unlikely to be able to fulfill even the most modest aims and ambitions that all parents have for their children-without suffering deep sadness and disappointment. Although everyone would like to spare children exposure to tragedy of any sort, the sharing of such an experience brings families close together and even though life is certainly changed, the cliché that it is not always for the worst is found to be true. The impact of mental handicap on the family will be different for the older children, who may have been able to appreciate the grief when the fact of handicap was established, either at the time of birth or later, than for children born subsequently who are less likely to be reported as having difficulties.

\section{Parental problems}

Unfortunately, the emotional trauma of having a child with a lasting handicap can be too much for some vulnerable personalities or fragile relationships. Early detrimental effects of the quality of the parents' relationship to each other have been noted within the first two years after the birth of a child with Down's syndrome. Children invariably do suffer when the relationship between their parents deteriorates to a situation of cold dislike or open hostility. Similarly, the sibling of the handicapped child is at risk when the initial grief felt by the parent has moved into a chronic depression. Sadly, these two problems often occur together as poor mental health in either parent is often found in conjunction with a bad marriage. Not only is the normal sibling more likely to show behavioural and emotional problems, but the mentally handicapped child is also similarly vulnerable and can show serious behaviour disorders, which can be particularly difficult to treat. $^{2}$

\section{Sharing of family burden}

For most families, the rearing of a mentally handicapped child, even when adequately supported by medical services, with appropriate schooling and the opportunity of respite care, and with attendance or mobility allowances, necessitates much hard work relentlessly increasing as the child grows older and heavier. However, this load almost invariably falls on the mother. ${ }^{3}$ Earlier work on siblings showed different effects on brothers and sisters, ${ }^{4}$ and an explanation to account for the greater vulnerability of older sisters (particularly those from larger, relatively disadvantaged families) was that they were more involved in the practical problems of care. When specifically asked about what they did at home, however, children attending a group for siblings of children with a mental handicap denied being asked to do more chores than were their contemporaries in school. ${ }^{5}$ The demands put upon the brothers and sisters was investigated in two more recent studies, and little evidence was found that they were being asked to carry a greater burden of household chores or minding a younger or more dependent sibling than a comparison group. ${ }^{67}$ Older sisters were not the Cinderellas of community care any longer: that role was almost exclusively put upon the mother. 
Severe behaviour problems, a common accompaniment of mental handicap in childhood, greatly increases the problems at home for the parents and often for the brothers and sisters as well.

\section{Deprivation of parental attention}

There might just not be enough of the mother's time or energy to go round. This situation can certainly happen and many families appreciate the chance to relax or have the sort of fun with their other children that is impossible in the company of the mentally retarded child. To be successful respite care needs to be seen as something positive. Linking with another family who can sometimes share the care of the more difficult member of the family, as would the ideal uncle or aunt, has been a very successful way of making respite care a positive experience all round.

Another possible myth is that parents commonly attempt to 'make up' to the handicapped child at the expense of their other normal children. Dividing attention equably among children of different ages with very different needs is a not uncommon problem of family life. No study has offered any objective evidence that parents of mentally handicapped children reserve significantly less time or attention for their normal children than do any other parents in what are regarded as normal families. On the contrary, many parents are very sensitive about the possibility of neglecting their other children. Most workers who study families in depth or over a long period are much impressed by the adaption and by the normality of those involved. ${ }^{1}$

\section{Excessive expectations}

It has also been suggested that parental ambition thwarted by the mental handicap of one child might be transferred in a detrimental way on to another child in the family. Most clinicians have seen such a situation arise but it is not common, certainly not inevitable nor even typical. Such increased expectations were seen in studies published 20 years ago when parents had little contact with the handicapped child and certainly no chance of feeling pride in any achievement. There are still families where the handicap of a child takes on an unusually great importance-for example, a handicapped first born son in many cultures.

\section{Embarrassment and stigma}

Attitudes towards mentally handicapped people, particularly children, have become much more positive over the past 20 years and this is mirrored in the studies of successive cohorts of families. It was not uncommon for the handicapped member of the family to have been admitted to long stay institutions and thereafter if not forgotten then never mentioned so that new members of the family might never know of the existence of such a person. When the secret has been revealed, as in the case of a family with a genetically determined disorder, the inquiries after the diagnosis have opened up deep rifts between members of the family. More open and accepting attitudes, which owe much to parent groups, mean that mentally handicapped children are now commonly seen with their families or schools enjoying ordinary activities in the community. Different cultures, however, within the United Kingdom, may still feel shamed by a handicapped child and fear returning to visit relatives in even countries in the European Community as well as developing countries because of ignorance, prejudice, and outright antagonism towards a handicapped child, which will extend also to a sibling.

Brothers and sisters reflect parental attitudes. It has been shown that when mothers and fathers were affectionate and actively encouraging their handicapped child then so were the siblings, who were also more often seen in a positive light by the parents. ${ }^{8}$ In research studies of families, most of whom rarely visited hospitals or clinics, much robust determination to make the best out of their child and the situation they found themselves in created a strong sense of unity involving both parents and the other siblings. In hospitals, particularly centres to which families are referred away from their local services, the disillusioned families who still search for diagnoses or answers to apparently intractable problems are more common. In this situation, the brothers and sisters often identify with the disappointment and hostility expressed by the parents towards doctors and other services. It is the bias made by the referral that makes this sort of family seem so familiar.

\section{Sociodemographic factors}

As with other children, there are other environmental influences on the brothers and sisters in families. For example, there is some evidence suggesting that it is easier for children if there is more than one normal sibling, as deviancy is lowest in sibships of three or four. ${ }^{4}$ Larger families are relatively common in families with a child with Down's syndrome in all social groups, but family size can not been seen as advantageous. Mental handicap in the family always brings hard work and has often crushed cherished hopes, but in conditions of social disadvantage, poorly paid unskilled work, 
unemployment, or bad housing it is particularly difficult for all children in the family. Some of the saddest families have been found among the ethnic minority groups as they had to contend with isolation and prejudice as well as the other social problems.

\section{Achievement at school}

Learning problems in brothers and sisters are more often found where no medical explanation could be given for the mental handicap itself. ${ }^{7}$ Medical diagnoses, such as demonstrable brain damage, metabolic disorders, and chromosomal anomalies, are more often found in the more severely handicapped, while mental handicap in the mild range is more often associated with cultural disadvantage. The intellectual abilities of siblings of children with a severe handicap are greater than those of siblings of children with a mild mental handicap. ${ }^{9}$ Brothers and sisters of children with Down's syndrome perform at school to a very similar standard to that of others in the same school class. When the siblings of children with no medical explanation for the handicap were compared with others in the same school class, there were significantly more among the sibling group with serious reading problems. In addition, such children were more often found in less advantaged areas where the others in the school had a higher rate of reading problems than did the sibling of a child with Down's syndrome or their control child in the same school class. Behaviour problems in the siblings were much more common in those who had significant problems with reading.

\section{Do the brothers and sisters of handicapped children need help?}

It is of course necessary that appropriate help be given to those children who are encountering major difficulties at school as a third of the siblings of children with no medical diagnosis were more than two years behind in reading. Similarly children in families who were being driven apart by marital disharmony or chronic mental illness in a parent may well require specific treatment for themselves as well as attention being paid to the underlying problem. But do these brothers and sisters need special help just because they are siblings of children with mental handicaps? Many object to the assumption that they do, just as they and their parents dislike being thought of as a handicapped family. As one remarked, 'I hate that word "sibling". It is as if there was something odd about me too'. Groups. not surprisingly, have not been conspicuously successful. Welcoming open days at the special schools showing how children with multiple disabilities can be taught, with demonstrations of the use of computers or instruction in a sign language such as Makaton, can be very helpful and much appreciated. It is no coincidence that many teachers, social workers, and nurses working in the field of mental handicap have a brother or sister with that disability.

Should specialist treatment for behaviour problems be offered to the retarded child and his family, getting to know the other children can be very helpful both in understanding the way the problem has arisen or been maintained and in continuing with treatment programmes. However, family treatment with a therapist who is ignorant about mental handicap can be a disaster. Treatment of all sorts must follow accurate assessment and the sharing as far as possible of knowledge about all the implications of the handicap.

What does seem to be helpful is to foster the self esteem of other children in the family by giving them the chance to shine, and it may be in a different direction. A counsel of perfection perhaps, but insistence on involvement in groups or family treatment can preclude that option. The other children do need information that can help them deal with ignorance or prejudice or can help them plan their own futures, particularly if the disorder concerned has a genetic basis.

\section{Conclusion}

There are many families who can prove that it is possible to be a loving and resourceful parent who can provide a stimulating and happy home to children of contrasting abilities and apparently conflicting needs. There is much to learn from such parents and their children that can help in understanding ordinary as well as extraordinary families. The provision of relevant services for children with disabilities including mental handicap and effective help for those who need it must follow an appreciative appraisal of families rather than a patronising assumption that all their individual quirks can be attributed to inevitable 'stress'.

\footnotetext{
References

1 Byrne EA, Cunningham CC, Sloper P. Families and their children with Down's syndrome: one feature in common. London: Routledge, 1988.

2 Gath A, Gumley D. Behaviour problems in retarded children with special reference to Down's syndrome. Br J Psychiatry 1986;149:156-61.

${ }^{3}$ Dupont A. A study concerning the time-related and other burdens when severely handicapped children are reared at home. In: Epidemiological Research as Basis for the Organisation of Extramural Psychiatry. Acta Psychiatr Scand 1980;62 (Suppl 285):2249-57.
} 


\section{Gath}

${ }^{4}$ Gath A. Sibling reactions to mental handicap: a comparison of the brothers and sisters of mongol children. Child Psychol Psychiatry 1974;15:187-98.

5 Hart D, Walters J. Brothers and sisters of mentally handicapped children. London: Thomas Coram Research Unit, University of London; 1979. (Research report.)

6 Lobato D, Barbour L, Hall LJ, Miller CT. Psychosocial characteristics of preschool siblings of handicapped and nonhandicapped children. J Abnorm Child Psychol 1987;15:329-38.

7 Gath A, Gumley D. Retarded children and their siblings. J Child Psychol Psychiatry 1987;28:715-30.

8 McHale SM, Sloan J, Simeonsson RJ. Sibling relationships of children with autistic, mentally retarded and nonhandicapped brothers and sisters. J.Autism Dev Disord 1986;16:399-413

9 Broman S, Nichols PL, Shaughnessy P, Kennedy W. Retardation in young children. A developmental study of cognitive deficit. New Jersey: Lawrence Erlbaum Associates, 1987.

A Gath Hilda Lewis House, Bethlem Royal Hospital, 579 Wickham Road, Shirley, Croydon CRO 8DR 